\title{
Association between socioeconomic status and HIV-associated oral lesions in Rio de Janeiro from 1997 to 2004
}

\author{
Cesar Werneck Noce ${ }^{(a)}$ \\ Sonia Maria Soares Ferreira ${ }^{(b)}$ \\ Arley Silva Júnior ${ }^{(c)}$ \\ Eliane Pedra Dias ${ }^{(d)}$ \\ (a) MSc in Pathology, Fluminense Federal \\ University, Rio de Janeiro, RJ, Brazil. \\ (b) PhD, Assistant Professor, Dental School, \\ Educational Foundation Jayme de Altavila \\ (FEJAL/CESMAC), Maceió, AL, Brazil. \\ (c) PhD, Assistant Professor, Dental School, \\ Gama Filho University, Rio de Janeiro, RJ, \\ Brazil. \\ (d) $\mathrm{MD}, \mathrm{PhD}$, Coordinator, Graduate Program, \\ Fluminense Federal University, Niterói, RJ, \\ Brazil.
}

\begin{abstract}
The prevalence of HIV-related oral lesions may vary according to socioeconomic status and antiretroviral therapy, among other factors. This study's intent was to evaluate the association between socioeconomic indicators, CD4+ counts and HIV-related oral lesions in the city of Rio de Janeiro, RJ, Brazil. A retrospective epidemiological analysis was performed of the medical records of HIV-positive patients that attended the Federal University of Rio de Janeiro between 1997 and 2004. Gender, age, mode of HIV transmission, level of education, monthly familial income, CD4+ counts and HIV-related oral lesions were assessed. For statistical analysis, the Chi-square test was used with a level of significance of 5\%. 254 medical records were reviewed: 83 women and 171 men. Monthly familial income below 2 minimum wages was associated with a higher prevalence of pseudomembranous candidiasis $(\mathrm{p}=0.024)$, while income above 10 minimum wages was associated with a higher prevalence of salivary gland disease $(\mathrm{p}=0.021)$. Lower socioeconomic status was associated with lower CD4+ counts ( $p=0.017)$. In this study, an association was noted between socioeconomic status, immune suppression and prevalence of oral lesions. However, further studies are warranted using other socioeconomic variables in order to better assess this relationship.
\end{abstract}

Descriptors: HIV; Oral manifestations; Social class.

\section{Corresponding author:}

Cesar Werneck Noce

Rua Cupertino Durão, 21/101 - Leblon

Rio de Janeiro - RJ - Brazil

CEP: 22441-030

E-mail: cesarnoce@globo.com 


\section{Introduction}

Oral lesions are frequent in HIV infection, especially candidiasis, oral hairy leukoplakia, Kaposi's sarcoma, non-Hodgkin lymphoma and periodontal disease. ${ }^{1}$ Some of these lesions, like candidiasis, are particularly important due to their relevance as clinical markers of immune suppression. ${ }^{2-4}$

Besides immune suppression, the prevalence of oral lesions may be influenced by the social context in which HIV-positive individuals are inserted. Grando et al..$^{5}$ (2003) and Challacombe et al. ${ }^{6}$ (2002) observed that improved socioeconomic status, as well as adequate medical care and education, exert an important influence on the prevalence of oral lesions.

According to UNAIDS ${ }^{7}$ (2006), in Latin America, HIV transmission is occurring in the context of factors common to most countries: widespread poverty and migration, insufficient information about epidemic trends outside major urban areas and rampant homophobia. In Brazil, there are 620,000 HIV-positive patients, with an increasing prevalence of HIV/AIDS in individuals with more than 40 years of age, women and with lower levels of education.,8

This social pattern has also been observed in the United States. The Centers for Disease Control and Prevention (CDC) ${ }^{9}$ (2005) reported that the HIV/ AIDS epidemic is concentrated in social groups that traditionally have limited access to prevention services, medical care and effective therapies.

Therefore, this study's intent was to perform a comparative analysis between socioeconomic indicators, CD4+ counts and oral lesions among patients attended in a referral center of dental treatment of HIV-positive patients in Rio de Janeiro, RJ, Brazil.

\section{Material and Methods}

The medical records of all HIV-positive patients who attended the Clementino Fraga Filho University Hospital and the Stomatology Clinic of the Federal University of Rio de Janeiro (UFRJ) between 1997 and 2004 were reviewed.

Sex, age, mode of HIV transmission, level of education, monthly familial income, CD4+ counts and type and site of HIV-associated oral lesions were assessed.
With regard to monthly familial income, this variable was categorized in this study according to the classification already present in the medical records. This classification was based on the national minimum wage (MW), defined annually by the Brazilian Government.

Level of education and monthly familial income are frequently used to estimate the socioeconomic status of an individual. ${ }^{10-13}$ Therefore, in this study, these variables were selected as proxy indicators of socioeconomic status and were categorized as follows:

1. Low socioeconomic status: 8 or less years of education or monthly familial income lower than $2 \mathrm{MW}$.

2. Medium socioeconomic status: 9 to 11 years of education or monthly familial income between 3 and $9 \mathrm{MW}$; or 9 to 11 years of education and monthly familial income lower than $9 \mathrm{MW}$.

3. High socioeconomic status: 12 years or more of education or monthly familial income higher than $10 \mathrm{MW}$.

Only definitively diagnosed oral lesions, as classified according to the revised classification of the EC-Clearinghouse on Oral Problems related to HIV Infection criteria (1993), ${ }^{1}$ were considered in this study. Immunological laboratory values were considered for the study only if obtained three months prior or one month after the oral examination.

To be included in the study, participants had to be 13 years of age or older and take the same antiretroviral therapy for at least 3 months. Patients excluded from the study were those who changed their antiretroviral therapy in less than 3 months, younger than 13 years of age, pregnant or on research with new antiretroviral drugs.

This study received the approval of the Ethics Committee, Federal University of Rio de Janeiro. The Chi-square test was used for statistical analysis, with a level of significance of $5 \%$.

\section{Results}

Two hundred and fifty four medical records were collected: $83(32.7 \%)$ women and $171(67.3 \%)$ men. Sexual transmission $(94.3 \%)$ followed by blood transfusion $(5.7 \%)$ were the most common catego- 
ries of mode of transmission.

Forty three percent of the patients were 30 to 39 years old $(43 \%)$, followed by 40 years and older (34.7\%) and 13 to 29 years of age $(22.3 \%)$.

With regard to level of education, the majority of patients had less than 8 years of education $(46 \%)$, followed by 9 to 11 years of education $(38.2 \%)$ and 12 years or more of education $(15.7 \%)$.

Information on monthly familial income was absent in 22 cases. The distribution of familial income was as follows: $2 \mathrm{MW}(57.8 \%), 3-4 \mathrm{MW}(23.7 \%)$, 5-9 MW (12.5\%), 10-19 MW (5.2\%) and 20 or more MW $(0.9 \%)$.

Based on the information about level of education and monthly familial income, all the medical records were classified by socioeconomic status as follows: $46.1 \%$ as medium, $35 \%$ as low and $18.9 \%$ as high socioeconomic status.

Oral lesions associated with HIV/AIDS were present in $35.8 \%$ of the cases. The distribution of oral mucosa sites affected by lesions was as follows: tongue $(21.7 \%)$, palate $(13 \%)$, gingiva $(10.3 \%)$, buccal mucosa $(7.1 \%)$, lips $(6.3 \%)$ and floor of the mouth $(2 \%)$.

The most frequently observed oral lesions were candidiasis (20.9\%), especially in its pseudomembranous (PC) and erythematous forms, followed by

Table 1 - Most frequently observed oral lesions.

\begin{tabular}{l|c|c}
\hline \multicolumn{1}{c|}{ Oral lesions } & $\mathrm{n}$ & $\%$ \\
\hline Candidiasis & 53 & 20.9 \\
- Erythematous candidiasis & 31 & 12.2 \\
- Pseudomembranous candidiasis & 28 & 11 \\
- Angular cheilitis & 11 & 4.3 \\
\hline Periodontal disease & 23 & 9.1 \\
- Linear gingival erythema & 18 & 7.1 \\
- Necrotizing ulcerative periodontitis & 05 & 2.0 \\
- Necrotizing ulcerative gingivitis & 02 & 0.8 \\
\hline Oral hairy leukoplakia & 20 & 7.9 \\
\hline Recurrent aphthous ulcers & 09 & 3.5 \\
\hline Oral warts & 03 & 1.2 \\
\hline Kaposi's sarcoma & 02 & 0.8 \\
\hline Lymphadenopathy & 02 & 0.8 \\
\hline HIV-associated salivary gland disease & 02 & 0.8 \\
\hline Labial herpes & 02 & 0.8 \\
\hline Necrotizing stomatitis & 01 & 0.4 \\
\hline
\end{tabular}

periodontal disease (PD) (9.1\%), oral hairy leukoplakia $(\mathrm{OHL})(7.9 \%)$, recurrent aphthous ulcers $(3.5 \%)$, Kaposi's sarcoma (KS) $(0.8 \%)$, oral warts $(1.2 \%)$, ulcer not otherwise specified (1\%), lymphadenopathy $(0.8 \%), \mathrm{HIV}$-associated salivary gland disease (SGD) $(0.8 \%)$, labial herpes $(0.8 \%)$ and necrotizing stomatitis $(0.4 \%)$ (Table 1$)$.

Gender and age showed no statistical significance with regard to level of education, monthly familial income and socioeconomic status. However, monthly familial income lower than $2 \mathrm{MW}$ was associated with a higher prevalence of PC $(\mathrm{p}=0.024)$, while income higher than $10 \mathrm{MW}$ was associated with a higher prevalence of SGD $(\mathrm{p}=0.021)$. Level of education from 9 to 11 years of education showed a higher prevalence of OHL ( $\mathrm{p}=0.009)$.

Patients with low socioeconomic status were associated with a higher prevalence of PC $(\mathrm{p}=0.033)$. On the other hand, high socioeconomic status was related to a higher prevalence of SGD $(\mathrm{p}=0.013)$ (Graph 1).

Also, socioeconomic status showed a statistically significant association with CD4+ counts ( $\mathrm{p}=0.017$ ). Low socioeconomic status was noted in $49.4 \%$ of patients with CD4+ counts below 199 cells $/ \mathrm{mm}^{3}$. On the other hand, medium or high socioeconomic status had CD4+ counts higher than 200 cells $/ \mathrm{mm}^{3}$ in $71.6 \%$ and $61.3 \%$ of the cases, re-

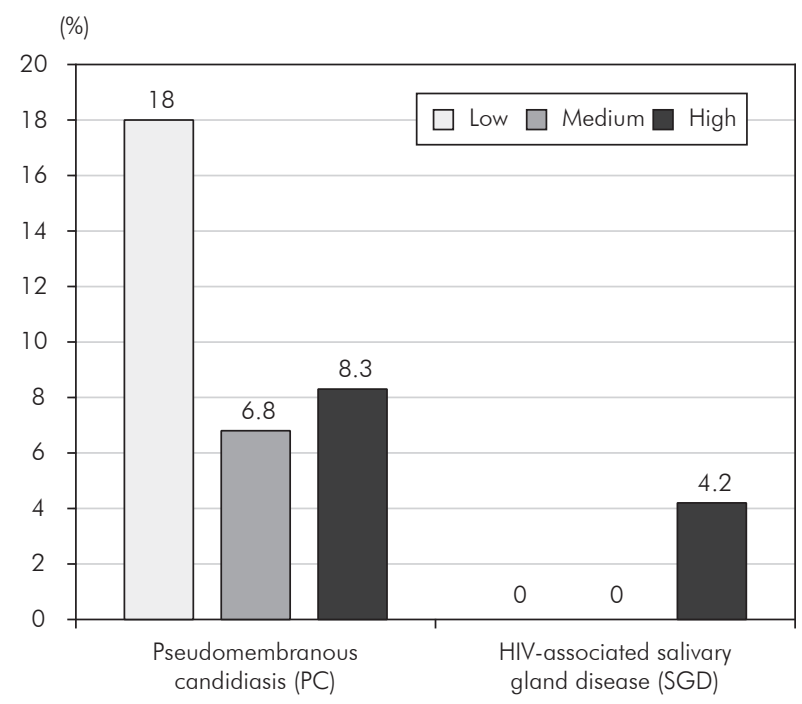

Graph 1 - Association between socioeconomic status and the prevalence of PC ( $p=0.033)$ and SGD ( $p=0.013)$. 
(\%)

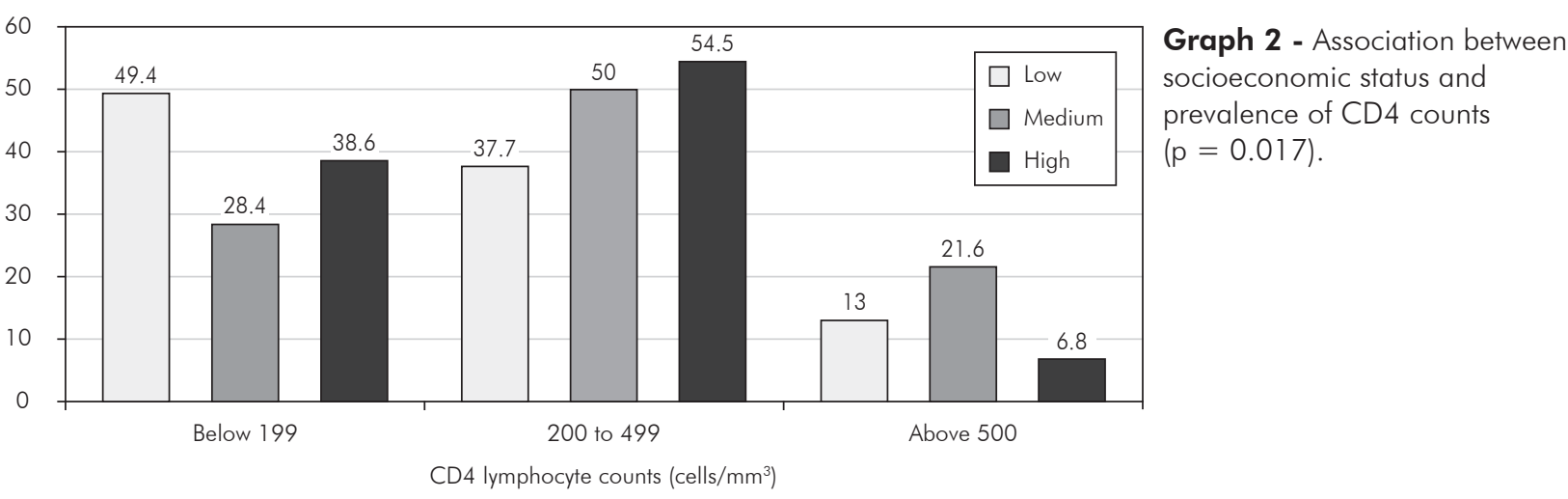

spectively (Graph 2).

\section{Discussion}

The Federal University of Rio de Janeiro (UFRJ) is an important referral center for the medical treatment of HIV-positive patients, including dental care, since 1988. Since then, although other centers have begun to attend HIV-positive patients, the UFRJ is still an important referral center of dental care for these patients.

Noce $^{14}$ (2006), using the same sample of this study, observed that individuals of higher socioeconomic status were more prevalent before 1996, i.e., before the introduction of highly active antiretroviral therapy (HAART). From 1997 to 2004, a higher prevalence of individuals with low socioeconomic status and 8 years or less of education was observed.

Therefore, in this study only data collected between 1997 and 2004 were used in order to reduce a possible bias between a higher socioeconomic status and oral lesions more prevalent before the introduction of HAART.

Arispe et al..$^{11}$ (2005) commented that the variable level of education is not applicable to children or young adults who have not completed their education, and is frequently overestimated in death certificates and have many different meanings across generations. The authors also noted that the variable income is frequently underreported and its significance varies over time.

In this study, this bias was reduced since the sample was collected from patients attended in a short period of time and no information was obtained from death certificates. Additionally, information regarding monthly familial income was only absent in 22 of the 254 medical records reviewed.

According to UNAIDS $^{7}$ (2006), more adult women than ever before are now living with HIV, with worldwide estimates of 17.7 million HIV-positive women in 2006. In this study, even though most patients were men, a high prevalence of HIV-positive women was observed, which may be attributed to this worldwide trend.

In Latin America, UNAIDS ${ }^{7}$ also observed that HIV transmission is occurring in the context of factors common to most countries: widespread poverty and migration, insufficient information about epidemic trends outside major urban areas and rampant homophobia. This social pattern has also been observed in the United States, where the HIV/AIDS epidemic is concentrated in social groups that traditionally have limited access to prevention services, medical care and effective therapies. ${ }^{9}$

In this study, $46.1 \%$ of the patients had 8 or less years of education, while $57.8 \%$ had monthly familial income lower than $2 \mathrm{MW}$. Therefore, $81.1 \%$ of the studied population was classified as having a low or medium socioeconomic status, which is in accordance with this social pattern of the HIV/ AIDS epidemic.

Also, in this study, statistically significant associations were noted between a higher prevalence of PC and a lower monthly familial income, as well as for a higher prevalence of OHL and a lower level of education. Both these lesions are highly associated with HIV/AIDS infection and may be considered as 
clinical markers of immune suppression..$^{15}$

An association was observed between monthly familial income higher than $10 \mathrm{MW}$ and a higher prevalence of SGD. This disease is part of the Diffuse Infiltrative Lymphocytosis Syndrome and indicates a better prognosis for the patient. ${ }^{16}$

Ramírez-Amador et al. ${ }^{17}$ (2006), in Mexico City, concluded that patients from a public clinic presented a higher prevalence of OHL, KS and PD in comparison with patients attended in a private clinic. The authors also emphasized that this finding was not related to viral load, CD4+ counts or duration of antiretroviral therapy.

In the present study, no association was observed with regard to KS or PD. This result might be due to a reduction in the prevalence of oral lesions following the introduction of HAART. ${ }^{15,16,18-20}$ The data used was collected from patients attended between 1997 and 2004, and since 1996 there is free distribution of antiretroviral drugs to Brazilians infected with the HIV virus.

With regard to CD4+ counts, an association was noted between a low socioeconomic status and CD4+ counts below 199 cells $/ \mathrm{mm}^{3}$. In Brazil, since 1996 there is free distribution of antiretroviral therapy to the Brazilian population, regardless of socioeconomic status. However, a difference in the perception of information related to personal health might explain this result.

Indeed, Biazevic et al. ${ }^{12}$ (2004) observed an association between socioeconomic status and perceived oral health among the elderly population in Santa Catarina. The authors suggested that people with higher consumption standards tend to be more critical about the perception of their oral health.

\section{References}

1. Classification and diagnostic criteria for oral lesions in HIV infection. EC-Clearinghouse on Oral Problems Related to HIV Infection and WHO Collaborating Centre on Oral Manifestations of the Immunodeficiency Virus. J Oral Pathol Med. 1993 Aug; 22(7):289-91.

2. Coogan MM, Greenspan J, Challacombe SJ. Oral lesions in infection with human immunodeficiency virus. Bull World Health Organ. 2005 Sep;83(9):700-6.
Grando et al. ${ }^{5}$ (2003) and Challacombe et al. ${ }^{6}$ (2002) observed that improved socioeconomic status, as well as adequate medical care and education, exert an important influence on the prevalence of oral lesions. In Latin America, UNAIDS ${ }^{7}$ also commented that the HIV/AIDS epidemic is spreading in accordance with the social context of this geographic region.

Tassinari et al. ${ }^{21}$ (2007), in Rio de Janeiro, observed that individuals with a lower level of education and lower income had a more deficient oral care. The authors attributed this result to a more difficult access to information and health care.

Salazar et al. ${ }^{22}$ (2006), in a study performed in Peru, also emphasized the influence of socioeconomic status on the health care of an individual. The authors observed that low-income and homosexual patients present a feeling of invulnerability towards the HIV/AIDS epidemic, even though these same individuals were often submissive to their sex partners and made very infrequent use of condoms.

\section{Conclusions}

In conclusion, this study observed an association between lower socioeconomic status, higher degree of immune suppression and higher prevalence of oral lesions. In Brazil, even though there is free distribution of antiretroviral therapy, the individual attitude towards the HIV/AIDS epidemic and personal care, as well as the perception of oral health related information and access to health care services, may vary according to the socioeconomic status. However, further studies are needed in order to assess the role of these variables in the prevalence of oral manifestations of HIV/AIDS in Rio de Janeiro, RJ, Brazil.

3. Hodgson TA, Greenspan D, Greenspan JS. Oral lesions of HIV disease and HAART in industrialized countries. Adv Dent Res. 2006 Apr;19(1):57-62.

4. Ranganathan K, Hemalatha R. Oral lesions in HIV infection in developing countries: an overview. Adv Dent Res. 2006 Apr;19(1):63-8.

5. Grando LJ, Yurgel LS, Machado DC, Nachman S, Ferguson F, Berentsen B et al. Associação entre manifestações estomatológicas e características socioeconômicas e culturais de crianças 
brasileiras e norte-americanas infectadas pelo HIV. Rev Panam Salud Publica. 2003 Aug;14(2):112-8.

6. Challacombe SJ, Coogan MM, Williams DM. Overview of the Fourth International Workshop on the Oral Manifestations of HIV Infection. Oral Dis. 2002;8(Suppl 2):9-14.

7. UNAIDS. AIDS epidemic update: special report on HIV/ AIDS: December 2006. Geneva: World Health Organization; 2006.

8. Ferreira S, Noce C, Silva Júnior A, Gonçalves L, Torres S, Meeks V et al. Prevalence of oral manifestations of HIV infection in Rio de Janeiro, Brazil, from 1988 to 2004. AIDS Patient Care STDs. 2007 Oct;21(10):724-31.

9. Centers for Disease Control and Prevention (CDC). Trends in HIV/AIDS diagnoses - 33 states, 2001-2004. MMWR Morb Mortal Wkly Rep. 2005;54(45):1149-53.

10. Amaral MA, Nakama L, Conrado CA, Matsuo T. Dental caries in young male adults: prevalence, severity and associated risk factors. Braz Oral Res. 2005 Oct-Dec;19(4):249-55.

11. Arispe IE, Holmes JS, Moy E. Measurement challenges in developing the National Healthcare Quality Report and the National Healthcare Disparities Report. Med Care. 2005 Mar;43(Suppl 3): I17-23.

12. Biazevic MGH, Michel-Crosato E, Iagher F, Pooter CE, Correa SL, Grasel CE. Impact of oral health on quality of life among the elderly population of Joaçaba, Santa Catarina, Brazil. Braz Oral Res. 2004 Jan-Mar;18(1):85-91.

13. Nomura LH, Bastos JLD, Peres MA. Dental pain prevalence and association with dental caries and socioeconomic status in schoolchildren, Southern Brazil, 2002. Braz Oral Res. 2004 Apr-Jun;18(2):134-40.

14. Noce CW. O efeito da terapia anti-retroviral na prevalência das manifestações bucais associadas à infecção pelo HIV/Aids [Dissertação de Mestrado]. Niterói: Universidade Federal Fluminense; 2006.

15. Hamza OJM, Matee MIN, Simon ENM, Kikwilu E, Moshi MJ, Mugusi F et al. Oral manifestations of HIV infection in children and adults receiving highly active anti-retroviral therapy [HAART] in Dar es Salaam, Tanzania. BMC Oral Health. [online] 2006 [cited 2006 Aug 18]. Available from: http://www.biomedcentral.com/1472-6831/6/12.

16. Greenspan D, Canchola AJ, MacPhail LA, Cheikh B, Greenspan JS. Effect of highly active antiretroviral therapy on frequency of oral warts. Lancet. 2001;357(9266):1411-2.

17. Ramírez-Amador V, Anaya-Saavedra G, Calva JJ, Clemades-Pérez-de-Corcho T, López-Martínez C, González-Ramírez I et al. HIV-Related Oral Lesions, Demographic Factors, Clinical Staging and Anti-Retroviral Use. Arch Med Res. 2006 Jul;37(5):646-54.

18. Ramírez-Amador V, Esquivel-Pedraza L, Sierra-Madero J, Anaya-Saavedra G, González-Ramírez I, Ponce-de-León S. The Changing Clinical Spectrum of Human Immunodeficiency Virus (HIV)-Related Oral Lesions in 1,000 Consecutive Patients: A 12-Year Study in a Referral Center in Mexico. Medicine. 2003 Jan;82(1):39-50.

19. Ranganathan K, Umadevi M, Saraswathi TR, Kumarasamy N, Solomon S, Johnson N. Oral lesions and conditions associated with human immunodeficiency virus infection in 1000 South Indian patients. Ann Acad Med Singapore. 2004 Jul;33(4 Suppl):37-42.

20. Umadevi KMR, Ranganathan K, Pavithra S, Hemalatha R, Saraswathi TR, Kumarasamy $\mathrm{N}$ et al. Oral lesions among persons with HIV disease with and without highly active antiretroviral therapy in southern India. J Oral Pathol Med. 2007 Mar;36(3):136-41.

21. Tassinari WS, León AP, Werneck GL, Faerstein E, Lopes CS, Chor $\mathrm{D}$ et al. Contexto sócio-econômico e percepção da saúde bucal em uma população de adultos no Rio de Janeiro, Brasil: uma análise multinível. Cad Saude Publica. 2007 Jan;23(1):127-36.

22. Salazar X, Cáceres C, Maiorana A, Rosasco AM, Kegeles S, Coates $\mathrm{T}$ et al. Influencia del contexto sociocultural en la percepción del riesgo y la negociación de protección en hombres homosexuales pobres de la costa peruana. Cad Saude Publica. 2006 Oct;22(10):2097-104. 